\title{
Not One, But Five: Virtual Screening-Driven Drug Discovery of SARS-CoV2 Enzyme Inhibitors Targeting Viral Attachment, Replication and Post-Translational Infection Mechanisms
}

\author{
Mark Tristan J. Quimque ${ }^{1,2,3, \dagger}$, Kin Israel R. Notarte ${ }^{4, \dagger}$, Rey Arturo T. Fernandez ${ }^{4}$, \\ Mark Andrew O. Mendoza ${ }^{1}$, Rhenz Alfred D. Liman ${ }^{2}$, Justin Allen \\ K. Lim ${ }^{1}$, Luis Agustin E. Pilapil ${ }^{1}$, Jehiel Karsten H. Ong ${ }^{1}$, \\ Adriel M. Pastrana ${ }^{4}$ \& Allan Patrick G. Macabeo ${ }^{1, *}$ \\ ${ }^{1}$ Laboratory for Organic Reactivity, Discovery and Synthesis (LORDS), \\ Research Center for the Natural and Applied Sciences, University \\ of Santo Tomas, Espana Blvd., Manila 1015, Philippines ${ }^{2}$ \\ ${ }^{2}$ The Graduate School, University of Santo Tomas, Espana Blvd., Manila 1015, Philippines \\ ${ }^{3}$ Chemistry Department, College of Science and Mathematics, Mindanao State \\ University - Iligan Institute of Technology, Tibanga, 9200 Iligan City, Philippines \\ 4 Faculty of Medicine and Surgery, University of Santo Tomas, \\ Espana Blvd., Manila 1015, Philippines \\ $\dagger$ These authors contributed equally to this work.
}

*Correspondence:

Dr. Allan Patrick Macabeo

Email: agmacabeo@ust.edu.ph; allanpatrick_m@yahoo.com

Contact no.: +63-2-3406-1611-4057 


\begin{abstract}
The novel coronavirus SARS-CoV2, the causative agent of the worldwide pandemic disease COVID-19, emerged in December 2019 forcing lockdown of communities in many countries. The absence of specific drugs and vaccines, the rapid transmission of the virus, and the increasing number of deaths worldwide have necessitated the need to discover substances that can be tapped for drug development. With the aid of bioinformatics and computational modelling, ninety seven secondary metabolites from fungi previously reported to exhibit antiviral properties were docked onto SARS-CoV2 proteins involved in viral attachment, replication and post-translational mechanisms followed by in silico ADMET prediction (absorption, distribution, metabolism, excretion and toxicity) of the hit compounds. Thus, two fumiquinazoline alkaloids quinadoline B (19), scedapin C (15), and the polyketide isochaetochromin D1 (8) exhibited high binding affinities depending on the target protein. The compounds were active against the cysteine proteases, papain-like protease (PLpro) and chymotrypsin-like protease (3CLpro) which are involved in posttranslational modifications, RNA-directed RNA polymerase (RdRp) which is essential in viral replication, non-structural protein 15 (nsp15) which is involved in evasion of host immunity, and the spike protein which is responsible for binding to GRP78. Quinadoline B (19) was predicted to confer favorable ADMET values, high gastrointestinal absorptive probability and poor blood-brain barrier crossing capacities.
\end{abstract}

Keywords: COVID-19; SARS-CoV2; fungal natural products; antiviral; molecular docking; ADMET 


\section{Introduction}

The family Coronaviridae is a large group of viruses associated with a number of respiratory infections in humans [1]. In 2019, a novel coronavirus, SARS-CoV2, previously known as 2019-nCov, emerged and caused a global pandemic. The virus is highly infectious resulting in over two million confirmed cases worldwide catapulting human death toll to more than one hundred twenty thousand since the beginning of the outbreak [2]. The present situation is worsened by the unavailability of viral therapeutics and biointerventions such as specific drugs and vaccines since SARS-CoV2 is a newly emerged pathogen [3]. Given the rippled effect of this pandemic where many countries are on lockdown and the economies are on the brink of collapse, there is an urgent need to discover effective therapeutic agents to combat the SARS-CoV2 virus. There is currently a growing interest to uncover SARSCoV2 pathogenesis that could aid in the discovery of potential inhibitors for drug development.

Modern drug discovery aided by advances in bioinformatics and computational modelling has enabled virtual screening of secondary metabolites for hit identification and lead optimization [4]. As a response to the COVID-19 pandemic, several studies utilized molecular docking for virtual screening and repurposing pre-existing drugs and natural products. This effort led to the identification of commercially available anti-polymerase drugs such as ribavirin and remdesivir as candidates for targeting RNA-directed RNA polymerase $(\mathrm{RdRp})$ [5]. In a separate study, Arya and co-workers constructed a homology model of the papain-like protease (PLpro) and identified 15 FDA-approved drugs such as chloroquine and formoterol with the potential to be used against the newly emerged coronavirus [6]. In addition, screening of purchasable antivirals on the chymotrypsin-like protease (3CLpro) molecular model led to the identification of sixteen drug candidates. Among these, ledipasvir and velpatasvir were the most promising drugs with minimal side 
effects [7]. However, efforts to discover multi-targeting, selective, druggable and less toxic compounds are also equally important and thus, warrant further investigations.

As a contribution to this global scientific undertaking to combat the pandemic COVID19 , our study centers on the exploitation of fungal secondary metabolites with profound antiviral activity on a range of other pathogenic viruses - human immunodeficiency virus (HIV), influenza virus, herpes simplex virus (HSV), and hepatitis $\mathrm{C}$ virus (HCV) - as potential drugs against SARS-CoV2. Through in silico molecular docking screening, we reported two fumiquinazoline alkaloids quinadoline $B$ (19), scedapin $C(\mathbf{1 5})$, and the polyketide isochaetochromin D1 (8) with strong inhibitory effects against the proteins involved in viral attachment (spike protein), replication (RdRp), post-translational infection mechanisms (PLpro and 3CLpro), and evasion of host immunity (non-structural protein 15, nsp15) in SARS-CoV2. In addition, computational ADMET was also determined to define the potential of these multi-targeting fungal natural products for lead optimization and drug development.

\section{Materials and Methods}

\section{Molecular docking}

Five target proteins crucial for the infectivity of SARS-CoV2 were selected as molecular targets. The homology model of the catalytic domains of the target proteins was generated in the SWISS-MODEL workspace (swissmodel.expasy.org/workspace) using as templates the high-resolution crystal structure of 3CLpro (PDB ID: 6LU7), PLpro (PDB ID: 6W9C), RdRp (PDB ID: 6M71), nsp15 (PDB ID: 6VWW), and the spike's protein binding domain to GRP78 (PDB ID: 6VXX).

A library of ninety seven secondary metabolites from marine and terrestrial fungi previously reported to inhibit human immunodeficiency virus (HIV), herpes simplex virus 
(HSV), hepatitis B virus (HBV), hepatitis C virus (HCV), influenza virus, tobacco mosaic virus, and enteroviruses were screened against the aforementioned target proteins.

Molecular docking experiments were performed on the UCSF Chimera platform [8]. The three-dimensional structures of the proteins were added in PDB formats while the ligands (fungal secondary metabolites) were rendered from SMILES notation or SYBYL mol2 file. Avogadro (version 1.1.1) an open-source molecular builder, was used to prepare the ligands [9]. Minimization and dock-prepping of ligand and protein structures were done using Antechamber [10]. The ligand was allowed to be flexible and torsion within a grid box encompassing the ligand-binding cavity of each enzyme, predicted using $\mathrm{COACH}$ algorithms [11]. With all docking parameters maintained at default values, molecular docking simulation was performed following the Broyden-Fletcher-Goldfarb-Shanoo (BFGS) algorithm of AutoDock Vina (version 1.1.2) [12]. Visualization and analysis of the enzyme-ligand complex conformation were carried out using UCSF Chimera and Biovia Discovery Studios (version 4.1).

\section{Drug-likeness, ADME, and toxicity prediction}

The computational prediction of the absorption, distribution, metabolism, and excretion (ADME) properties of hit compounds were done using SwissADME software (Molecular Modeling Group, Swiss Institute of Bioinformatics, 2019). Pharmacokinetic profiles were evaluated according to Lipinski's 'rule-of-five' which analyzes the biochemical features of a drug that may influence its absorption and permeation across cell membranes. Lipinski's criteria states that for a compound to exhibit drug likeness, at least three of the following criteria must be fulfilled: molecular weight $<500$ Daltons $(\mathrm{Da})$, calculated lipophilicity (Log P) $<5$, number of hydrogen-bond acceptors $<10$, and number of hydrogen-bond donors $<5$ [13]. Furthermore, OSIRIS property explorer program (Thomas Sander, Idorsia Pharmaceuticals Ltd., 2017) was employed for in silico toxicity prediction which takes into 
account the potential mutagenicity, tumorigenicity, irritant effects, and reproductive toxicity of the hit compounds [14]. Using the same software, the solubility (Log S) of hits which is a determining factor for absorption and bioavailability was also predicted. As previously elucidated, values of Log S equivalent or greater than -4 indicate favorable solubility [15].

\section{Results}

Owing to the potential of cysteine proteases (3CLpro and PLpro), RdRp, nsp15, and the spike proteins as drug targets for SARS-CoV2, ninety seven fungal natural products 1-97 previously reported to exhibit antiviral properties were virtually screened for in silico inhibitory activity. Using the UCSF Chimera platform, a molecular docking approach was performed to simulate and visualize protein-ligand interactions of the different fungal metabolites against the SARS-CoV2 proteins. Of the ninety seven metabolites screened, twenty five compounds 1-25 (Figure 1) showed high binding affinities to at least one of the five target proteins (Table 1).

\section{Cysteine proteases (PLpro and 3CLpro)}

Cysteine proteases constitute important antiviral target proteins that are highly conserved between the human coronavirus SARS-CoV and SARS-CoV2 [31]. PLpro, a part of nsp3, functions to cleave the $N$-terminus of the polyprotein to release itself along with nonstructural proteins (nsps) 1 and 2. 3CLpro cleaves the remaining nsp's, releasing a total of 16 nsps required for viral replication. Hence, cysteine proteases may be utilized as drug targets to inhibit post-translational modification and activation of viral enzymes. This is best exemplified by withanolides from Solanaceae family and several andrographolide derivatives from Scutellaria baicalensis active against cysteine proteases [31,32]. Since these secondary metabolites in SARS-CoV2 remain as attractive targets for antiviral therapy, we explored the potential of fungal compounds for their binding affinity towards PLpro and 3CLpro. 
Table 1. In silico docking results of the top-ranked fungal metabolites 1-25 against five SARS-CoV2 proteins.

\begin{tabular}{|c|c|c|c|c|c|c|}
\hline \multirow[b]{2}{*}{ Compound } & \multirow[b]{2}{*}{ Antiviral Activity } & \multicolumn{5}{|c|}{ Binding Energy (kcal/mol) } \\
\hline & & PLpro & 3CLpro & RdRp & nsp15 & $\begin{array}{c}\mathrm{S} \\
\text { Protein }\end{array}$ \\
\hline Altertoxin V (1) & Anti-HIV [16] & -9.4 & -7.2 & -8.5 & -8.1 & -7.1 \\
\hline Altertoxin II (2) & Anti-HIV [16] & -9.2 & -7.5 & -8.3 & -7.6 & -7.6 \\
\hline Penicillixanthone A (3) & Anti-HIV [17] & -9.5 & -8.2 & -8.1 & -6.9 & -8.1 \\
\hline Cytochalasin Z8 (4) & Anti-HIV [18] & -10.3 & -7.9 & -9.6 & -8.5 & -8.1 \\
\hline Stachybotrosin D (5) & Anti-HIV [19] & -9.5 & -6.5 & -7.8 & -7.8 & -7.1 \\
\hline Chloropupukeanolide A (6) & Anti-HIV [20] & -10.0 & -7.5 & -7.7 & -6.8 & -8.1 \\
\hline Phomasetin (7) & $\begin{array}{l}\text { HIV-1 Integrase } \\
\text { Inhibitor [21] }\end{array}$ & -9.6 & -7.2 & -6.9 & -6.9 & -8.3 \\
\hline Isochaetochromin D1 (8) & $\begin{array}{l}\text { HIV-1 Integrase } \\
\text { Inhibitor [22] }\end{array}$ & -9.9 & -7.9 & -8.4 & -9.1 & -9.5 \\
\hline Aspergilol H (R) (9) & $\begin{array}{c}\text { Anti-Herpes simplex } \\
\text { [23] }\end{array}$ & -9.6 & -7.9 & -7.6 & -8.2 & -9.1 \\
\hline Aspergilol H (S) (10) & $\begin{array}{l}\text { Anti-Herpes simplex } \\
\text { [23] }\end{array}$ & -9.2 & -8.3 & -7.7 & -8.1 & -9.2 \\
\hline $\begin{array}{l}\text { 11a-Dehydroxyiso- } \\
\text { terreulactone A (11) }\end{array}$ & $\begin{array}{c}\text { Anti-Herpes simplex } \\
{[24]}\end{array}$ & -8.9 & -8.9 & -9.1 & -8.4 & -10.2 \\
\hline Arisugacin A (12) & $\begin{array}{l}\text { Anti-Herpes simplex } \\
\text { [24] }\end{array}$ & -10.0 & -8.0 & -8.5 & -8.5 & -9.2 \\
\hline Aspernolide A (13) & $\begin{array}{c}\text { Anti-Herpes simplex } \\
{[24]}\end{array}$ & -9.2 & -7.1 & -7.5 & -7.5 & -9.3 \\
\hline Rhodatin (14) & Anti-Hepatitis C [25] & -9.0 & -7.1 & -7.9 & -7.9 & -9.9 \\
\hline Scedapin C (15) & Anti-Hepatitis C [26] & -10.9 & -8.6 & -9.2 & -8.9 & -9.4 \\
\hline Scequinadoline A (16) & Anti-Hepatitis C [26] & -9.1 & -8.7 & -9.1 & -7.9 & -8.5 \\
\hline 14S-Oxoglyantrypine (17) & Anti-influenza [27] & -9.6 & -8.4 & -8.3 & -7.4 & -7.6 \\
\hline Deoxynortryptoquivaline (18) & Anti-influenza [27] & -9.6 & -7.6 & -7.4 & -7.1 & -8.0 \\
\hline Quinadoline B (19) & Anti-influenza [27] & -10.6 & -8.3 & -9.8 & -9.1 & -10.5 \\
\hline Norquinadoline A (20) & Anti-influenza [27] & -10.9 & -8.1 & -8.5 & -8.6 & -8.3 \\
\hline Asperterrestide A (S) (21) & Anti-influenza [28] & -8.9 & -8.3 & -7.6 & -7.3 & -8.7 \\
\hline Asperterrestide A (R) (22) & Anti-influenza [28] & -8.9 & -8.4 & -7.6 & -7.4 & -9.7 \\
\hline Rubrolide S (23) & Anti-influenza [29] & -8.7 & -7.7 & -7.4 & -7.8 & -10.3 \\
\hline Isoaspulvinone (24) & Anti-influenza [30] & -7.7 & -7.4 & -7.1 & -8.6 & -9.7 \\
\hline Pulvic acid (25) & Anti-influenza [30] & -7.9 & -6.6 & -7.5 & -8.5 & -9.3 \\
\hline
\end{tabular}



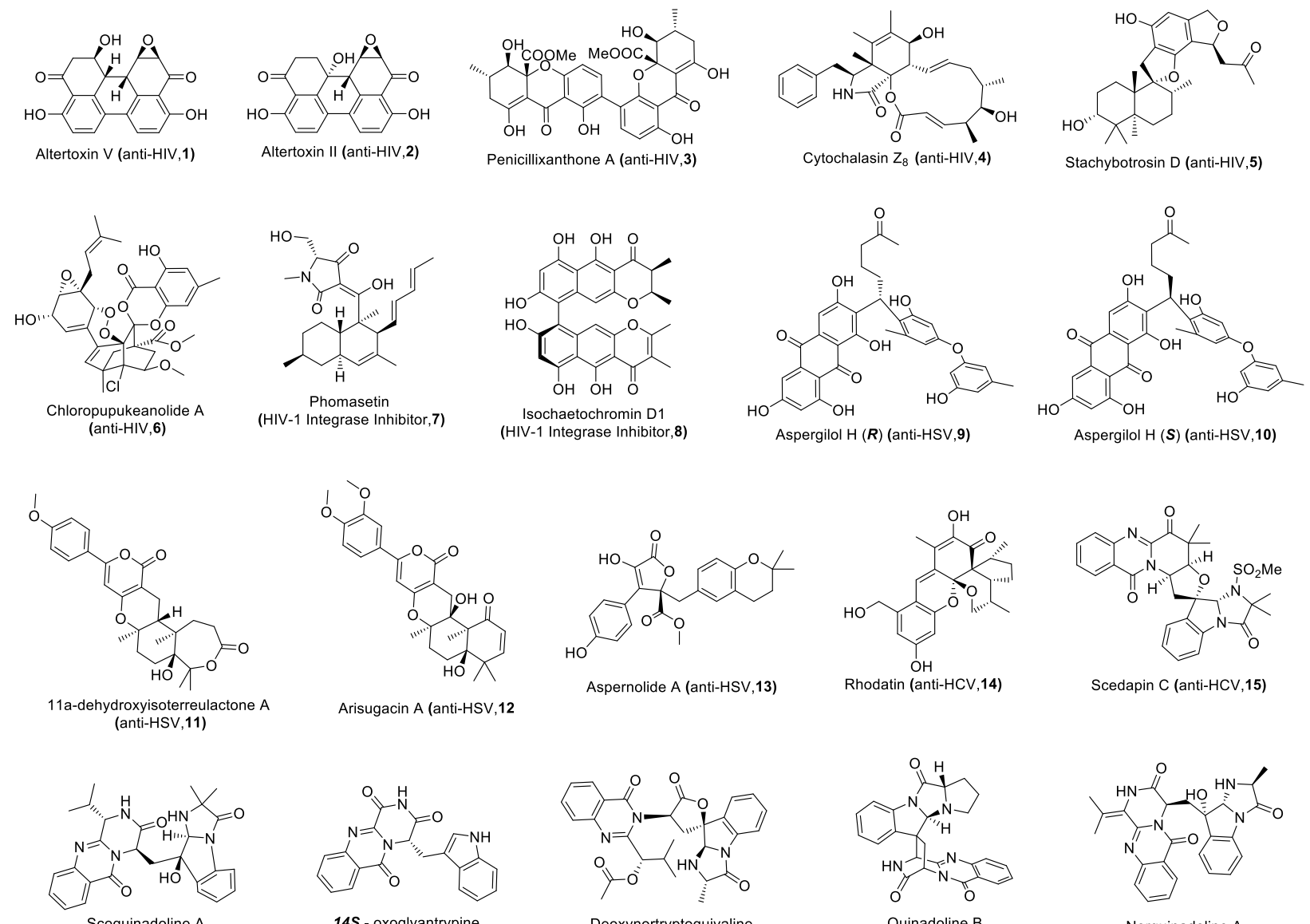

Deoxynortryptoquivaline
(anti-influenza,18)

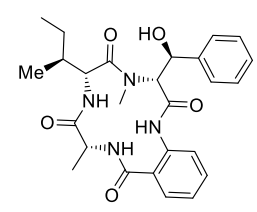

Asperterrestide $\mathrm{A}(\boldsymbol{S})$ Asperterrestide $\mathrm{A}(\mathbf{S})$
(anti-influenza,21)
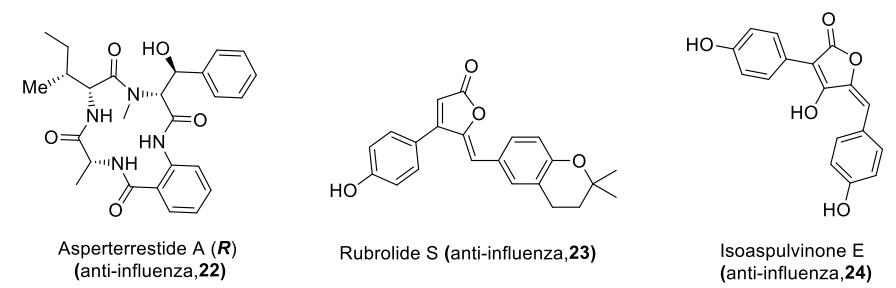

Norquinadoline A

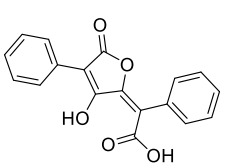

Pulvic Acid (anti-influenza,25)

Figure 1. Structures of fungal secondary metabolites 1-25 with in silico antagonism to SARS-CoV2.

Through in-silico-based screening, we reported thirteen fungal secondary metabolites displaying high affinity towards PLpro with binding energies (BE's) ranging from -9.5 to $10.9 \mathrm{kcal} / \mathrm{mol}$ (Table 1). We also screened the docking mechanism of lopinavir, an antiretroviral protease inhibitor used as a trial drug for SARS-CoV2. Interestingly, the fungal metabolites showed better binding compared to the reference drug lopinavir at -6.9 and -7.6 $\mathrm{kcal} / \mathrm{mol}$ against PLpro and 3CLpro, respectively. Among these compounds, the fumiquinazoline marine alkaloids scedapin C (15) and norquinadoline A (20) demonstrated 
highest affinity to PLpro, both with BE's of $-10.9 \mathrm{kcal} / \mathrm{mol}$. Another quinazoline alkaloid quinadoline B (19) also showed high affinity with BE's of -10.6 kcal/mol. Alkaloid 15 was isolated from the marine-derived fungus Scedosporium apiospermum F41-1 and displayed significant antiviral activity against hepatitis $C$ [26]. During the post-dock analysis, this fumiquinazoline alkaloid was noted to be bound to the putative binding site of PLpro through H-bonding with two ketones of the quinazolinedione core against Arg712. Additionally, the indole moiety is hinged to the enzyme's pocket via pi-cation intermolecular bonding with Lys711, pi-pi stacking with His342, and pi-alkyl interaction with Ala579. On the other hand, alkaloids 19 and $\mathbf{2 0}$ were previously isolated from the mangrove-derived fungus Cladosporium sp. PJX-41 and showed activity against influenza A (H1N1) [27]. The topscored pose of $\mathbf{2 0}$ is tightly nestled to the PLpro's binding site, stabilized mostly by van der Waals forces. Two H-bonds further strengthened its interaction with the enzyme, particularly between the carbonyl oxygens of the pyrazinoquinozolinedione core with Lys711 and Arg712. Similarly, 19 interacted with PLpro's binding site via H-bonds with Lys711 and Arg355. The presence of a fused phenyl ring in the latter interacted with amino acid residues Leu557, Ala579, and Ile580 through pi-alkyl interactions. The reference drug lopinavir likewise formed H-bonds with Lys711 and Arg558. Comparison of the docking behavior of the top three inhibitors for SARS-CoV2 PLpro revealed that these alkaloids -scedapin C (15), quinadoline B (19) and norquinadoline A (20) - all contain a quinazolinone core primarily involved in interacting with PLpro's putative binding site. Between compounds $\mathbf{1 9}$ and $\mathbf{2 0}$, the latter gave a higher binding energy probably due to the presence of two ketone groups in the quinazolinone core responsible for two intermolecular hydrogen bonds and the lack of spiro junction which is present in alkaloids $\mathbf{1 5}$ and 20, allowing a more relaxed conformational flexibility for enhanced non-covalent interactions with SARS-CoV2 PLpro catalytic residues. 

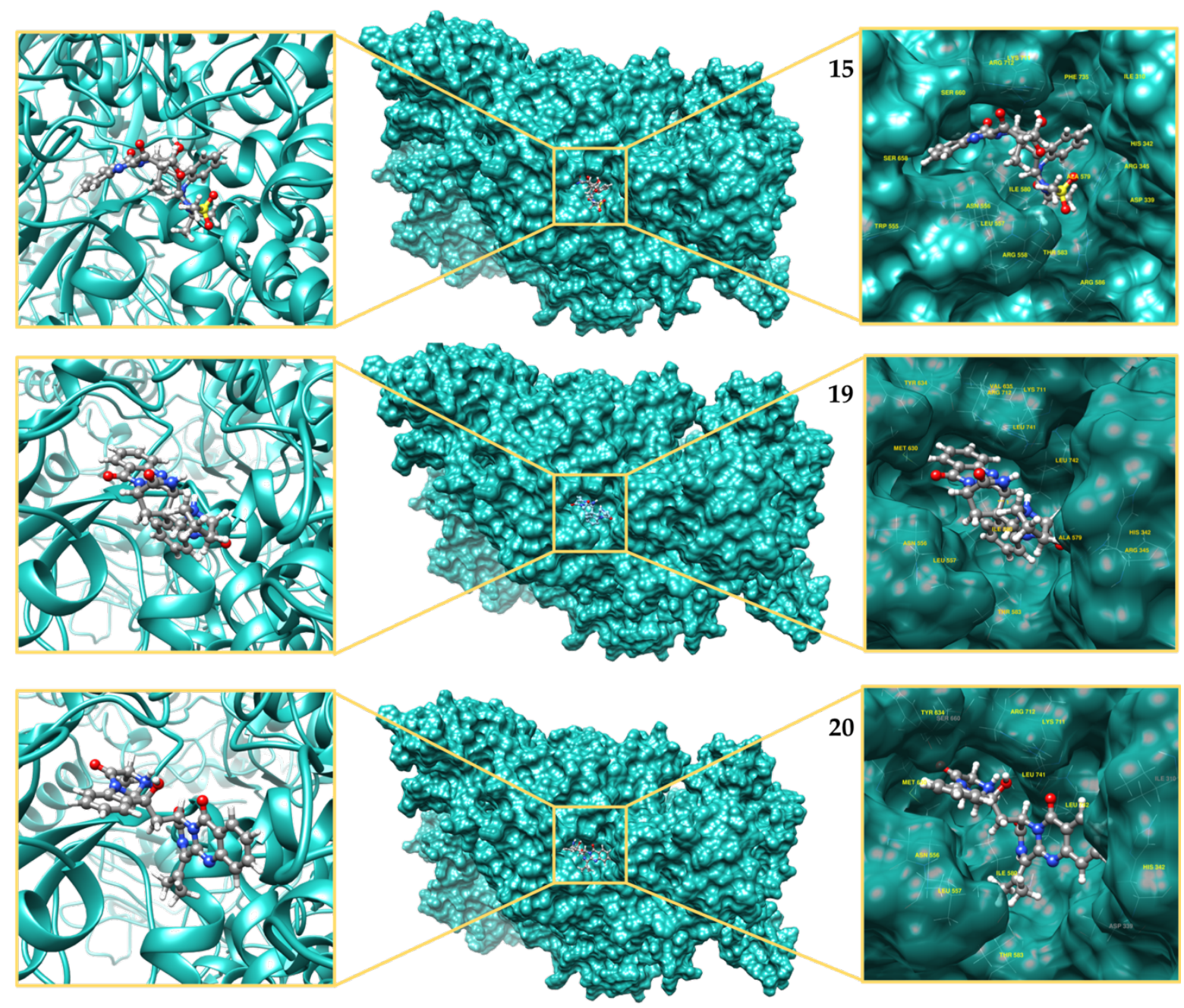

Figure 2. Docked poses of scedapin C (15), quinadoline B (19), and norquinadoline A (20) against SARS-CoV2 PLpro.

The 3CLpro enzyme functions by cleaving the polyprotein at 11 distinct sites to generate other non-structural proteins vital in viral replication. Thus, drugs that target this protease play a critical role in inhibiting the replication of the virus. The 3CLpro monomer has three domains, wherein the active site, housing the catalytic dyad (Cis145 and His41), is located between domains I and II. The third domain is connected to the rest of the protein structure by a long loop and this gap contains a larger pocket relative to the active site [31]. To assess the binding activity of the various fungal metabolites to 3CLpro, each was docked directly to the active site of the enzyme. Fourteen compounds were found to have relatively high affinity with BE's ranging from -7.9 to $-8.9 \mathrm{kcal} / \mathrm{mol}$ (Table 1 ). The most notable inhibitor is the anti- 
HSV metabolite from the marine-derived fungus Aspergillus terreus [24], 11adehydroxyisoterreulactone A (11), with a binding energy of $-8.9 \mathrm{kcal} / \mathrm{mol}$. The results of the docking analysis indicated that $\mathbf{1 1}$ is bound to the catalytic residue His41 through $p i-p i$ stacking with the pyranone ring fused in its polycyclic core. The enzyme-ligand complex is further stabilized by H-bonding and pi-alkyl interactions with its methoxyphenyl substituent. An unbiased (blind) docking was also performed for this compound in order to assess the preferential attachment of the ligand to the active site as opposed to other binding pockets. Interestingly, 11 (unbiased $\mathrm{BE}=-8.9 \mathrm{kcal} / \mathrm{mol}$ ) adapts to the same docking mechanism within the binding pocket of the catalytic dyad. Alkaloids scedapin C (15) and scequinadoline A (16) also showed significant binding affinities towards 3CLpro with BE's of -8.6 and -8.7 $\mathrm{kcal} / \mathrm{mol}$, respectively. Both compounds were isolated from the marine fungus Scedosporium apoispermum and displayed significant antiviral activity against hepatitis $\mathrm{C}$ [26]. In the case of compound 16, it is bound to the catalytic residue, His41, via two H-bonds with a carbonyl oxygen of the quinazolinone core and a hydroxyl group. Two other H-bonds were observed for Asn142 and Gly143 as well as pi-sulfur bond between Met49 and the indole moiety. The quinazoline core of $\mathbf{1 5}$, on the other hand, interacted with 3CLpro through pi-sulfur bonding with the catalytic amino acid Cys145 and pi-pi stacking with Met165. Its indole moiety is linked to His41 and Met49 by means of pi-pi stacking and pi-alkyl interaction, respectively. The presence of an indole moiety and a pyramidoquinazolinone core in both scedapin C (15) and scequinadoline A (16) is generally responsible for these two to exhibit notable in silico inhibitory activity against 3CLpro through strong interaction with the enzyme's catalytic dyad. Although both alkaloids have comparable binding energies, 16 gave a slightly stronger attachment (higher BE) because of four H-bonds (mostly by the ketone groups) with the amino acid residues as opposed to $\mathbf{1 5}$ with mostly pi interactions. 

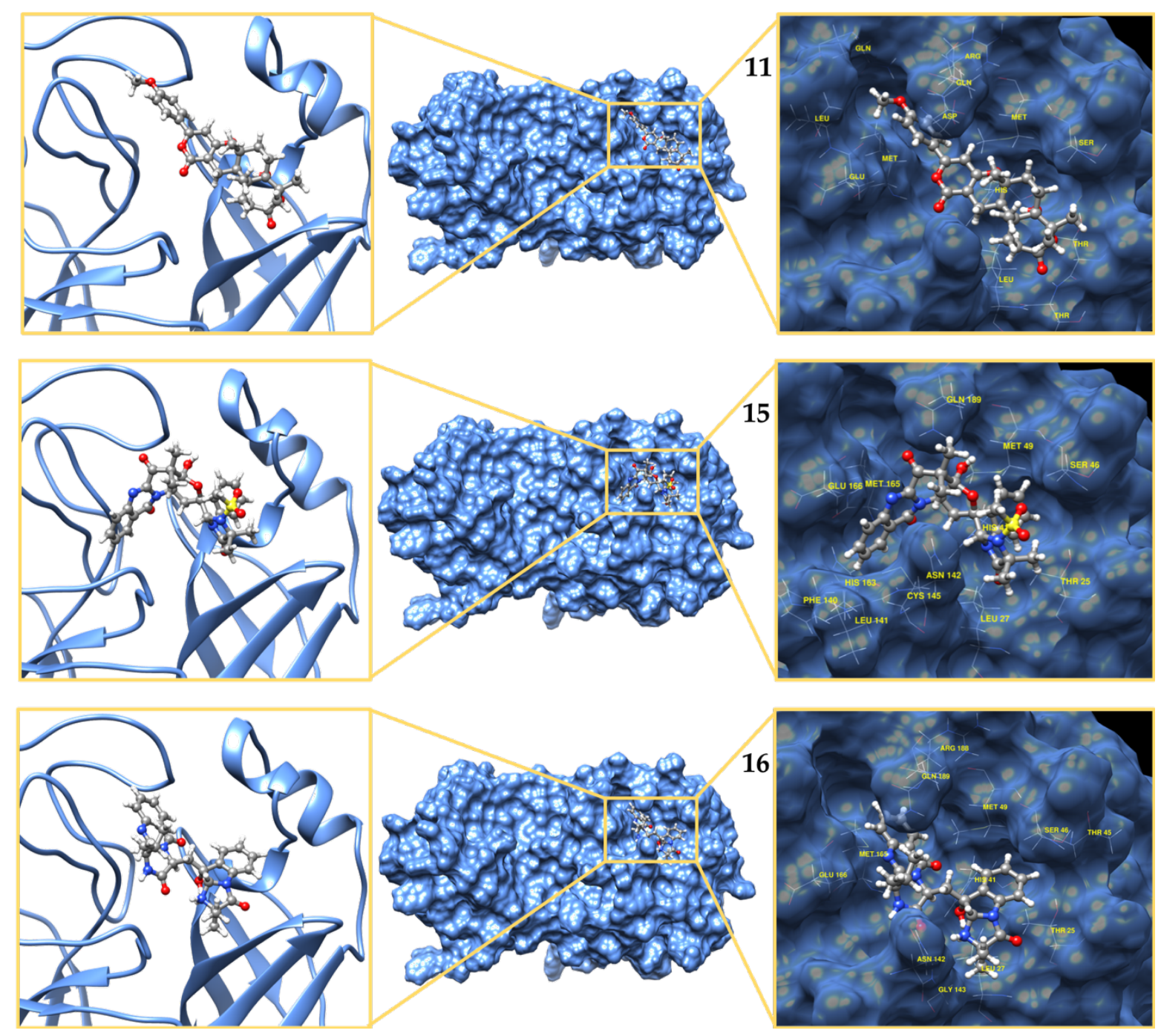

Figure 3. Docked poses of 11-dehydroxyisoterreuloactone (11), scedapin C (15), and scequinadoline A (16) against SARS-CoV2 3CLpro.

\section{RNA-directed RNA polymerase (RdRp)}

The RdRp of SARS HCoV is the closest strain to SARS-CoV2. Thus, the SARS-CoV2 RdRp model, consisting of 801 amino acids, was designed using the SARS HCoV RdRp as a homolog. The active site of RdRp is highly conserved and contains aspartate residues that protrude from the beta-turn joining the $\beta 15$ and $\beta 16$. With a vital role in viral genome replication, the active site residues of $\operatorname{RdRp}$ and most of the 5- $\AA$-region surrounding it are surface accessible and can bind to free nucleotides, including ATP, GTP, CTP, and UTP [5]. 
Similar to the viral proteases, RdRp is regarded as a molecular target for the development of new drugs against SARS-CoV2.

In this study, twelve secondary metabolites from fungi were detected to have high affinity for RdRp with binding energies ranging from -8.1 to $-9.8 \mathrm{kcal} / \mathrm{mol}$ (Table 1 ). Interestingly, the same group of secondary metabolites that showed the greatest binding affinities to cysteine proteases was also very potent against RdRp. Quinadoline B (19) had the highest binding affinity for RdRp with a BE of $-9.8 \mathrm{kcal} / \mathrm{mol}$. Compound 19's attachment to RdRp's binding site is due to the participation of two particular moieties. In its quinazolinone core, H-bonding can be observed between Gln73 as well as pi-cation and $p i$ alkyl interactions with Arg569 and Ala686, respectively. The indoline moiety of 19 is affixed to Tyr689, Ala580 and Ala688 residues through pi-pi stacking and pi-alkyl interactions. Other notable secondary metabolites are cytochalasin Z8 (4) and scedapin C (15) with RdRp BE's of -9.6 and $-9.2 \mathrm{kcal} / \mathrm{mol}$, respectively. For compound 4 , there were two conventional hydrogen bonds demonstrated by the hydroxy substituent of the macrocylic core (with Ser682) and the pyrrolidinone carbonyl oxygen (with Arg569). Several pi-pi stacking and pialkyl interactions were also observed against Tyr689, Ala580, Lys577, Leu576, Lys500, and Ile495. Compound $\mathbf{1 5}$ showed two conventional hydrogen bonds between a hydroxy substituent against Lys593 and Cys813. Also, in its quinazolinone core, the following interactions were observed: $p i$-alkyl with Ile589 and Leu758 and pi-sulfur with Cys813. Interestingly, these fungal metabolites showed higher BE's to RdRp than the reference prodrug favipiravir, docked in its active form favipiravir-ribofuranosyl-5'-triphosphate (favipiravir-RTP) with a binding energy of $-7.6 \mathrm{kcal} / \mathrm{mol}$. The docked poses of compounds 4, 15 and 19 are shown in Figure 6. Since RdRp is an essential protein encoded in all RNAcontaining viruses, such as SARS-CoV2, responsible for catalyzing the synthesis of the RNA complementary strand, we expect that compounds with antiviral activities against RNA- 
based viruses would be good candidates for potential RdRp inhibition. The results of this study, expectedly, revealed that the top three RdRp inhibitors: quinadoline B (19), cytochalasin Z8 (4), and scepadin C (15) were previously known to exhibit activities against RNA-based viruses, specifically HIV, influenza, and hepatitis C, respectively.
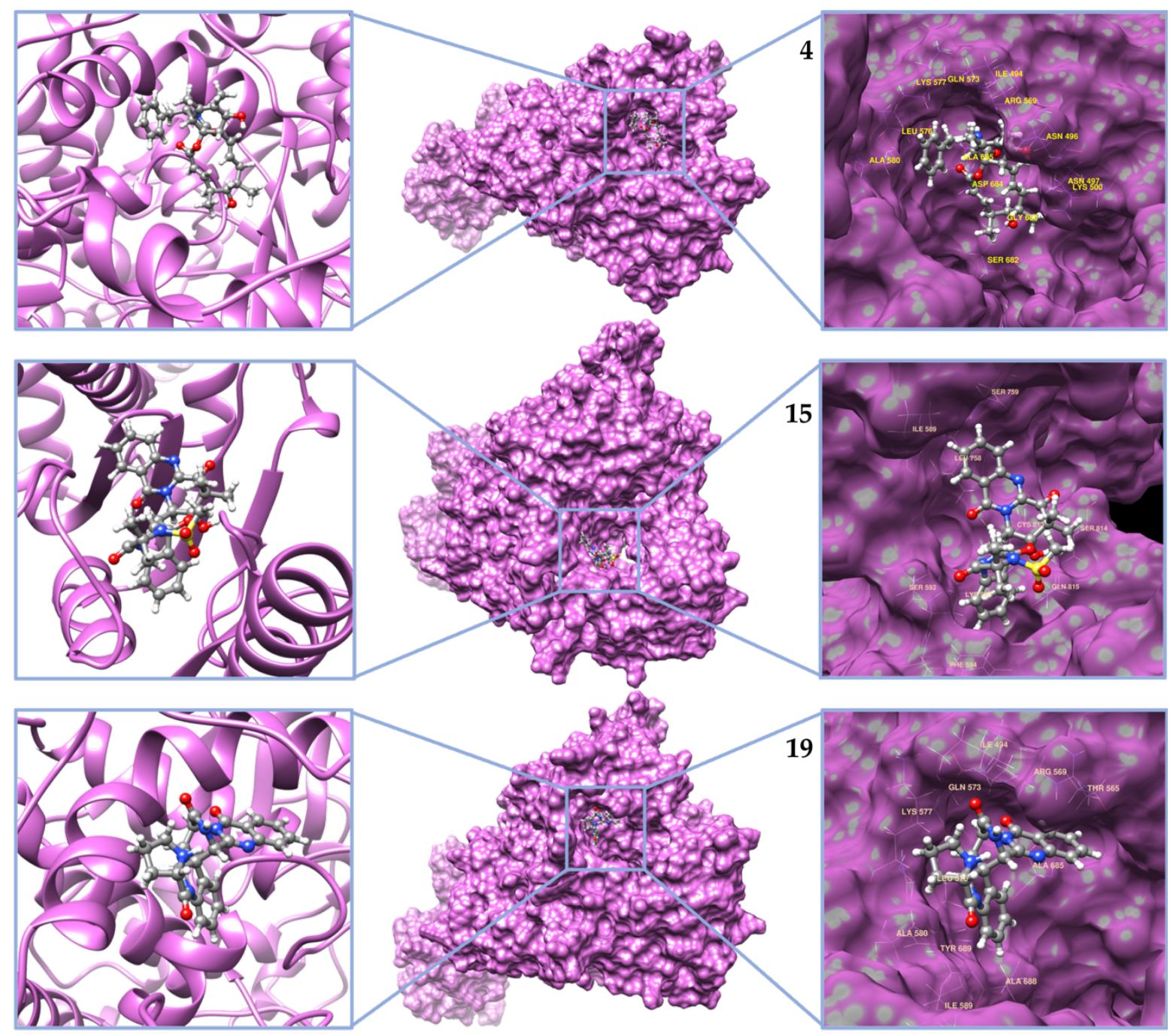

Figure 4. Docked poses of cytochalasin Z8 (4), scedapin C (15), and quinadoline B (19) against SARS-CoV2 RdRp.

Non-structural protein 15 (nsp15)

Nsp15 is an endoribonuclease that cleaves 3' of uridylates through a ribonuclease A (RNase A)-like mechanism [33]. It is not required for viral replication to occur but it inhibits detection of the host immune system. It does this by preventing simultaneous activation of 
host cell dsRNA sensors [34]. The structure of SARS-CoV2 nsp15 is quite similar to other coronavirus nsp15 monomers, which consists of three distinct regions: the $N$-terminal domain, a subsequent middle domain, and a catalytic $C$-terminal nidoviral RNA uridylatespecific endoribonuclease domain. Generally, for coronaviruses, the $C$-terminal domain houses the active site of the enzyme, specifically the proposed catalytic triad His235, His250, and Lys290 [35].

From the results of our screening, we identified twelve fungal metabolites with high affinity to nsp15 with BE's ranging from -8.1 to $-9.1 \mathrm{kcal} / \mathrm{mol}$ (Table 1 ). Two secondary metabolites namely isochaetochromin D1 (8) and quinadoline B (19) exhibited remarkable binding mechanisms to nsp15, both having BE of $-9.1 \mathrm{kcal} / \mathrm{mol}$. Compound $\mathbf{8}$ from Fusarium sp. was previously reported to interfere with HIV-integrase activity [22]. The best docking pose of $\mathbf{8}$ is attached to the binding domain via H-bonding with Val292 and catalytic residue His250. Several pi interactions were observed due to the presence of a polyaromatic core in 8. Furthermore, van der Waals (VDW) forces enhanced the stabilization of the ligand-enzyme complex, particularly against His235 and Lys290 along with other residues in the catalytic zone. Compound 19, on the other hand, showed notable interaction with the catalytic triad through pi-cation intermolecular bonding with Lys290 and VDW affinity with His235 and His250. Also, 19 exhibited H-bonding with Val292 and pi-pi/pi-alkyl interactions with Tyr343, Lys345, and Leu346. Another metabolite with interesting binding affinity towards nsp15 is the quinazoline alkaloid scedapin $\mathrm{C}(\mathbf{1 5})$, with $\mathrm{BE}=-8.9 \mathrm{kcal} / \mathrm{mol}$. Similar to the two compounds, 15 hinged itself to the catalytic triad via pi-pi stacking of its indole moiety against His235 and VDW affinity with His250 and Lys290. Other interactions of 15 include H-bonding with Thr341 and pi-pi stacking with Tyr343, both directed at the quinazolinone core. These results were compared to the binding behavior of benzopurpurin B, a potent inhibitor against SARS-CoV nsp15 endoribonuclease activity in vitro [31]. The said standard displayed a relatively good binding affinity with a $\mathrm{BE}$ of $-9.4 \mathrm{kcal} / \mathrm{mol}$. Although the $\mathrm{BE}$ of 
the standard is slightly higher compared to the three aforementioned fungal metabolites, all shared a similar binding pattern, hinging on nsp15's catalytic triad of the C-terminal domain through H-bonding, pi interactions, and VDW stabilization.
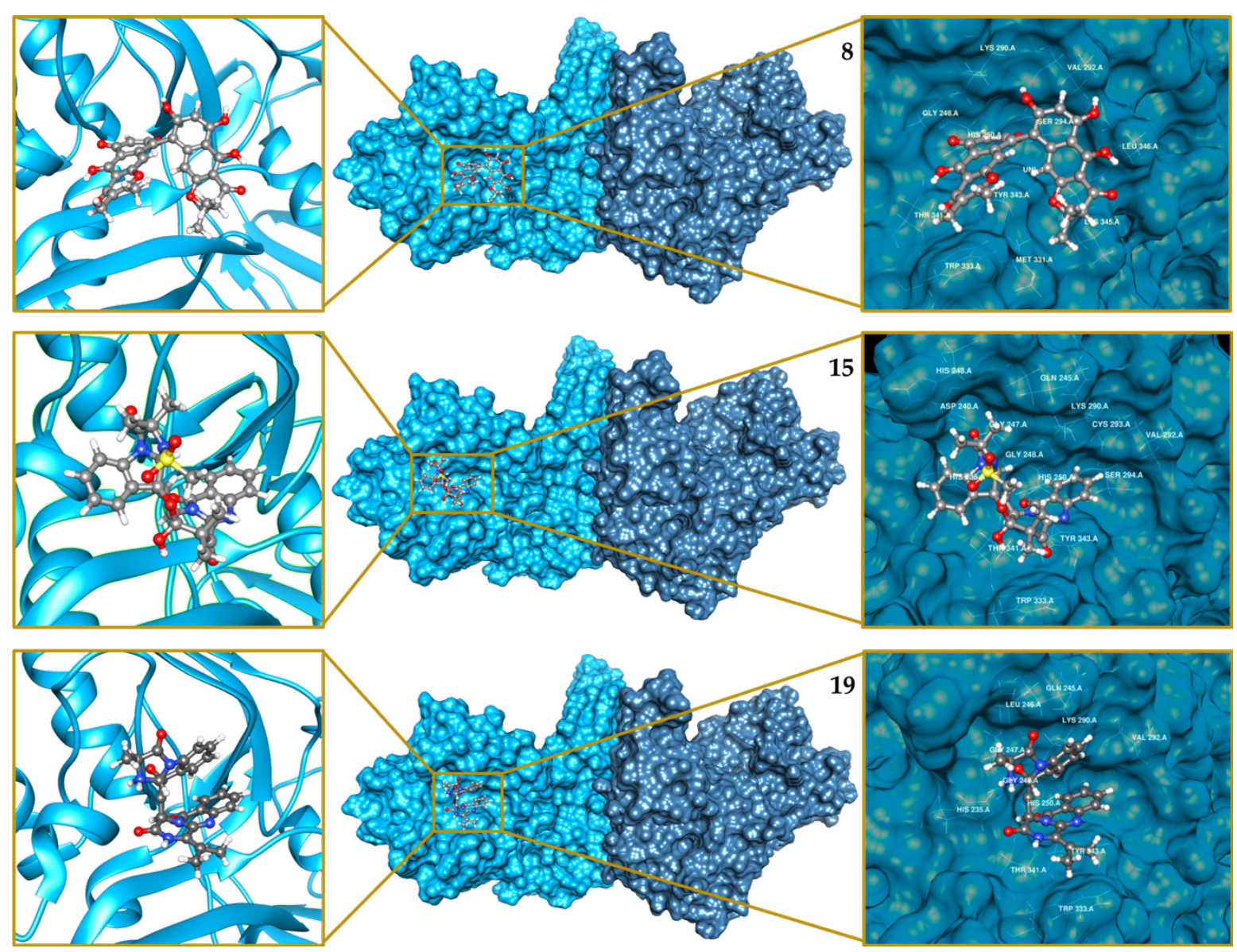

Figure 5. Docked poses of isochaetochromin D1 (8), scedapin C (15), and quinadoline B (19) against SARS-CoV2 nsp15.

\section{S protein (spikes)}

The spike protein is a homo-trimer protruding from the outer surface of the virion and serves as the major driving force for host cell recognition and entry. It is among the four structural proteins encoded by the viral RNA in addition to nsp 1-16. Although the primary entry of the virus is mediated by ACE2 receptors forming complexes with spike proteins, previous study demonstrated via molecular docking that there might be four regions in the spike that may act as binding sites for the glucose-regulated protein 78 (GRP78) [36]. Being 
a master chaperone protein, GRP78 is found in the lumen of the endoplasmic reticulum (ER) where it regulates important cellular processes, such as protein folding, cell death, and cell differentiation [37]. During cellular stress, however, GRP78 is overexpressed which increases the chance for it to be translocated from the ER to the cell membrane. Once in the cell membrane, GRP78 is susceptible to virus recognition by its substrate-binding domain (SBD) facilitating viral invasion [38]. This GRP78-mediated entry of the virus has also been observed in MERS-CoV which is a close relative of SARS-CoV2 [39]. Thus, inhibiting the interaction between the SARS-CoV2 spike protein and the host cell receptor GRP78 offers the possibility of decreasing the rate of viral infection [38].

Using fungal natural products 1-97, the binding between Region IV (C480- C488) of the spike protein model and GRP78 was challenged. Via molecular-docking-based screening, thirteen secondary compounds from fungi were identified to exhibit favorable binding to the spike protein with BE's ranging from -9.1 to $-10.5 \mathrm{kcal} / \mathrm{mol}$ (Table 1$)$. Of these, quinadoline B (19), rubrolide S (23), and 11a-dehydroxyisoterreulactone A (11) were the most promising with BE's of $-10.5,-10.3$, and $-10.2 \mathrm{kcal} / \mathrm{mol}$, respectively. It is worth noting that quinadoline B (19) as a multi-targeting compound antagonizes not only the spike proteins, but also the cysteine proteases, RdRp and nsp15. Meanwhile, 11a-dehydroxyisoterreulactone A (11), a territrem derivative previously isolated from the marine-derived fungus Aspergillus terreus showed to inhibit HSV-1 in vitro [24]. The major ligand-enzyme interactions of compound 19 at the supposed GRP78-binding region of the trimeric spike protein include the following: $p i$-sulfur bonding with Cys454, pi-alkyl with Ala444, pi-pi stacking with Phe430, and $p i$ anion interaction with Asp441. At the same putative binding site, compound 11 exhibited a conventional hydrogen bond between the pyranone moiety and Ala449. The phenol substructure of 11 displayed pi-pi/pi-anion interplay with Phe430, Asp441, and Asn343. Another potential inhibitor of SARS-CoV2 spikes is rubrolide S (23) isolated from the marine-derived fungus Aspergillus terreus OUCMDZ-1925 with known inhibitory property 
against Influenza A (H1N1) [29]. Compound 23's attachment to Region IV of the spike protein is due to H-bonding between the carbonyl oxygen of its furanone moiety against Glu445 and Tyr447. Moreover, the phenol substituent is stabilized by pi-anion attraction with Asp441 while the rest of the structure is stabilized by VDW forces. Compounds 11, 19 and 23 showed a more promising binding affinity than the reference drug umifenovir, an inhibitor of viral spikes, with a BE of only $-7.1 \mathrm{kcal} / \mathrm{mol}$. Thus, the following results generated via molecular docking open another probable use of fungal secondary metabolites. To the best of our knowledge, this is the first molecular docking experiment that targeted the binding domain of the spike protein to GRP78.
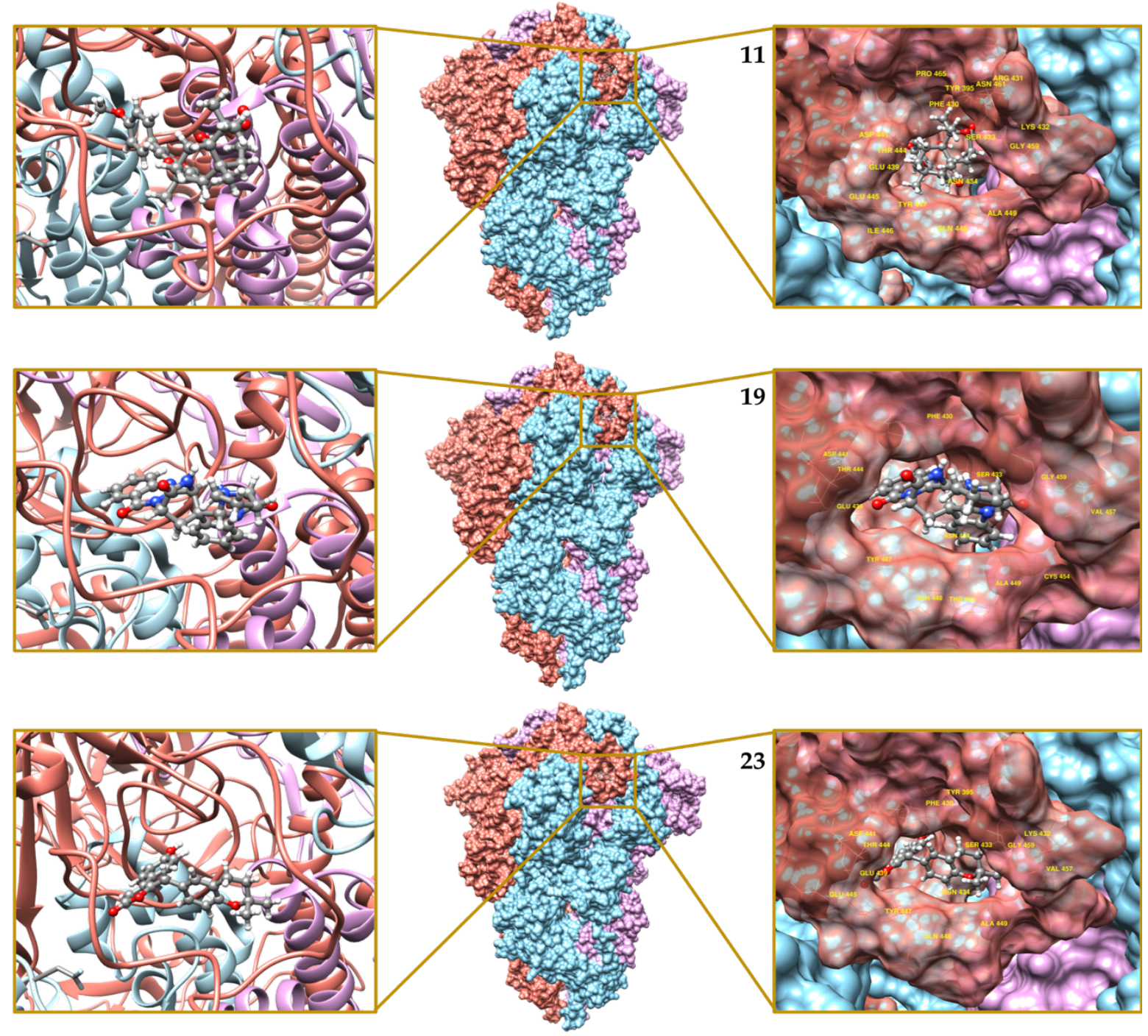

Figure 6. Docked poses of 11-dehydroxyisoterreuloactone (11), quinadoline B (19), and rubrolide S (23) against SARS-CoV2 spike protein. 


\section{In silico ADMET and drug-likeness}

The twenty five high dock-scoring compounds were also submitted for in silico ADME (absorption, distribution, metabolism, excretion) screening using SwissADME [40] to predict their overall pharmacokinetic behavior. The druggability of each compound was assessed based on Lipinski's Rule of Five, which is primarily focused on the prediction of the following descriptors: molecular weight, lipophilicity (reported as octanol-water partition coefficient), and the number of hydrogen bond donors and acceptors. The corresponding results are summarized in Table 2. Likewise, the BOILED-Egg (brain or intestinal estimated permeation predictive model), which is an intuitive graphical plot of the functions of lipophilicity and apparent polarity as described by the parameters WLOGP (atomistic octanol-water partition coefficient) and TPSA (topological polar surface area), respectively, was used to predict passive intestinal absorption and brain permeation of the compounds (Figure 7). Compounds located in the yellow region (yolk) have a high probability of BBB penetration while those in the white region have the propensity for passive absorption through the GI tract. Of the five metabolites, 11a-dehydroxyisoterreulactone A (11), quinadoline B (19), and norquinadoline A (20) were predicted to have good gastrointestinal (GI) absorption. They also exhibited low blood-brain barrier (BBB) penetration as reflected by their high topological surface area (TPSA). Despite having good binding affinity to all viral proteins, scedapin C (15) and isochaetochromin D1 (8) were predicted to be poorly absorbed in the GI tract hence explaining their location outside the white portion of the BOILED-egg model. Since the compounds are considered for oral delivery, they were also analyzed using the Lipinski's rule of 5: a rule that qualitatively assesses the drug-likeness of the candidate compounds [40]. Of these, fungal compounds 11, 19, and 20 exhibited good bioavailability and drug-likeness by fulfilling Lipinski's criteria. Apart from fulfilling the criteria, it is important to highlight that these fungal metabolites have good solubility which reflects good absorption, movement in the bloodstream and better elimination by the urinary tract [21]. 
Quinadoline B (19), having an $S \log$ value of -3.87 , has the best solubility among the multitargeting metabolites.

Table 2. Lipinski's Rule of Five for ADME analysis of compounds 1-25.

\begin{tabular}{c|c|c|c|c|c|c}
\hline Compound & $\begin{array}{c}\text { MW } \\
(<\mathbf{5 0 0})\end{array}$ & $\begin{array}{c}\text { \#H acceptors } \\
(<\mathbf{1 0})\end{array}$ & $\begin{array}{c}\text { \#H-bond } \\
\text { donors }(<\mathbf{5})\end{array}$ & $\begin{array}{c}\text { Lipophilicity } \\
\text { MLogP }(<\mathbf{5})\end{array}$ & $\begin{array}{c}\text { Lipinski } \\
\text { \#violations }\end{array}$ & $\begin{array}{c}\text { Drug } \\
\text { Likeness }\end{array}$ \\
\hline $\mathbf{1}$ & 318.32 & 4 & 1 & 1.58 & 0 & yes \\
$\mathbf{2}$ & 350.32 & 6 & 3 & 0.47 & 0 & yes \\
$\mathbf{3}$ & 638.57 & 14 & 6 & -1.36 & 3 & no \\
$\mathbf{4}$ & 465.58 & 5 & 3 & 2.83 & 0 & yes \\
$\mathbf{5}$ & 428.56 & 5 & 2 & 2.89 & 0 & yes \\
$\mathbf{6}$ & 643.08 & 11 & 2 & 2.09 & 2 & no \\
$\mathbf{7}$ & 413.55 & 4 & 2 & 2.39 & 0 & yes \\
$\mathbf{8}$ & 544.51 & 10 & 6 & 0.48 & 2 & no \\
$\mathbf{9}$ & 598.6 & 10 & 6 & 1.26 & 2 & no \\
$\mathbf{1 0}$ & 598.6 & 10 & 6 & 1.26 & 2 & no \\
$\mathbf{1 1}$ & 468.54 & 7 & 1 & 2.78 & 0 & yes \\
$\mathbf{1 2}$ & 496.55 & 8 & 2 & 1.57 & 0 & yes \\
$\mathbf{1 3}$ & 424.44 & 7 & 2 & 2.09 & 0 & yes \\
$\mathbf{1 4}$ & 398.45 & 6 & 3 & 1.69 & 0 & yes \\
$\mathbf{1 5}$ & 564.61 & 9 & 1 & 0.97 & 2 & no \\
$\mathbf{1 6}$ & 487.55 & 6 & 3 & 1.63 & 0 & yes \\
$\mathbf{1 7}$ & 358.35 & 4 & 2 & 1.84 & 0 & yes \\
$\mathbf{1 8}$ & 516.55 & 8 & 1 & 2.61 & 1 & yes \\
$\mathbf{1 9}$ & 439.47 & 5 & 1 & 2.00 & 0 & yes \\
$\mathbf{2 0}$ & 471.51 & 6 & 3 & 1.36 & 0 & yes \\
$\mathbf{2 1}$ & 480.56 & 5 & 4 & 0.86 & 0 & yes \\
$\mathbf{2 2}$ & 480.56 & 5 & 4 & 0.86 & 0 & yes \\
$\mathbf{2 3}$ & 348.39 & 4 & 1 & 3.29 & 0 & yes \\
$\mathbf{2 4}$ & 296.27 & 5 & 3 & 1.32 & 0 & yes \\
$\mathbf{2 5}$ & 308.28 & 5 & 2 & 1.76 & 0 & yes \\
\hline & & & & & &
\end{tabular}

A prediction of the toxicities, such as mutagenicity, tumorigenicity, irritant effect and reproductive toxicity, of the top-ranked compounds was also performed using OSIRIS Property Explorer. The toxicity risks and significant solubility of the compounds are presented in Table 3. Of the five multitargeting compounds, 11a-dehydroxyisoterreulactone A (11), scedapin C (15), and norquinadoline A (20) did not demonstrate any form of toxicity. Isochaetochromin D1 (8), however, was predicted to exhibit tumorigenicity and reproductive toxicity. Considering its good oral biovailability and druggability, quinadoline B (19), 
despite being a high-risk irritant, still remains a promising drug candidate for SARS-CoV2 because it did not confer mutagenic, tumorigenic, and reproductive toxicities.

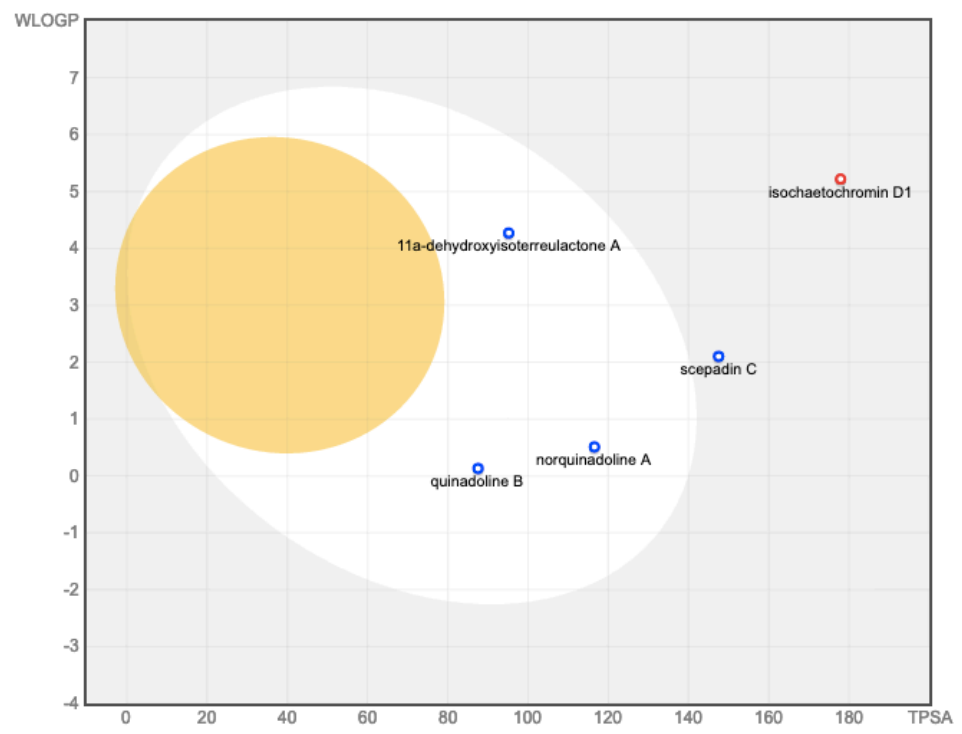

Figure 7. Prediction of gastrointestinal (GI) tract and brain permeation of the top five multitargeting hit fungal metabolites - isochaetochromin D1 (8), 11adehydroxyisoterreulactone A (11), scedapin C (15), quinadoline B (19), norquinadoline A (20) - by brain or intestinal estimated permeation predictive model (BOILED-Egg) method. 
Table 3. Predicted toxicity parameters and solubility of compounds 1-25.

\begin{tabular}{|c|c|c|c|c|c|}
\hline \multirow[b]{2}{*}{ Compound } & \multicolumn{4}{|c|}{ Toxicity } & \multirow{2}{*}{$\begin{array}{c}\text { Solubility } \\
\quad(\log S)\end{array}$} \\
\hline & Mutagenicity & Tumorigenicity & Irritant Effect & $\begin{array}{c}\text { Reproductive } \\
\text { Toxicity }\end{array}$ & \\
\hline 1 & None & None & None & None & -2.56 \\
\hline 2 & Medium Risk & None & High Risk & None & -5.12 \\
\hline 3 & None & None & None & None & -5.35 \\
\hline 4 & None & None & None & None & -4.21 \\
\hline 5 & None & None & High Risk & None & -4.8 \\
\hline 6 & High Risk & High Risk & High Risk & High Risk & -5.17 \\
\hline 7 & None & None & None & None & -3.38 \\
\hline 8 & None & High Risk & None & Medium Risk & -7.92 \\
\hline 9 & High Risk & None & High Risk & None & -8.32 \\
\hline 10 & High Risk & None & High Risk & None & -8.32 \\
\hline 11 & None & None & None & None & -4.71 \\
\hline 12 & None & None & None & None & -4.19 \\
\hline 13 & None & None & None & High Risk & -3.69 \\
\hline 14 & None & None & None & None & -3.95 \\
\hline 15 & None & None & None & None & -4.37 \\
\hline 16 & None & None & None & None & -4.05 \\
\hline 17 & None & None & None & None & -3.31 \\
\hline 18 & None & None & None & None & -4.48 \\
\hline 19 & None & None & High Risk & None & -3.87 \\
\hline 20 & None & None & None & None & -4.0 \\
\hline 21 & None & None & None & None & -3.4 \\
\hline 22 & None & None & None & None & -3.4 \\
\hline 23 & None & None & None & High Risk & -4.51 \\
\hline 24 & None & None & None & High Risk & -3.02 \\
\hline 25 & None & Medium Risk & None & None & -2.82 \\
\hline
\end{tabular}

\section{Discussion}

The elucidation of the structure and function of proteins associated with SARS-CoV2 encouraged the search for potential enzyme inhibitors that may alter viral attachment, replication, and maturation infection mechanisms. Natural products are valuable source of drug inspirations that form the cornerstone of modern pharmaceutical care [41]. Secondary metabolites from fungi have been successfully developed into several drug medications that include but are not limited to antineoplastics, antibiotics, and antivirals [42]. Due to the 
immense range of habitats that fungi inhabit and their need to compete against a diverse array of organisms, fungi have developed numerous ways to survive [43]. They can be grown with relative ease and have many characteristics that offer great promise for application in medicine. Efforts along this area have been highlighted in several fungal genera that produce secondary metabolites displaying a wide range of biological activities [44-50].

To any drug discovery and development program, understanding the pathogenesis of the disease is vital. Based on recent studies, the pathogenesis of viral infection begins when the viral spike proteins interact with host cell receptors. This is followed by endocytosis and eventually uncoating of the virus inside the host cell [51]. The uncoated viral RNA is consequently used as template to directly translate polyprotein $1 \mathrm{a} / 1 \mathrm{ab}(\mathrm{pp} 1 \mathrm{a} / \mathrm{pp} 1 \mathrm{ab})$ whose function is to encode nsp 1-16. This includes the cysteine proteases, PLpro and 3CLpro, which are associated with nsp3 and nsp5, respectively. These proteases cleave and activate other nsps such as nsp12 and 15. Nsp12 is also known as RdRp and is important in viral replication while nsp15 evades host dsRNA sensors [52]. With reports describing the role of ACE2 for viral entry, a recent study demonstrated that the chaperone protein glucoseregulated protein 78 or GRP78 localized in the lumen of the endoplasmic reticulum, can be translocated to the cell membrane during cellular stress [36]. Upon integration in the cell membrane, GRP78 mediates the secondary entry of SARS-CoV2 virus. Thus, targeting virulent factors that mediate viral attachment, replication, and host immunity evasion are key strategies for anti-COVID-19 drug discovery and development. Figure 8 illustrates the infection mechanism, pathways and/or virulence factors targeted for inhibition against SARS-CoV2. 


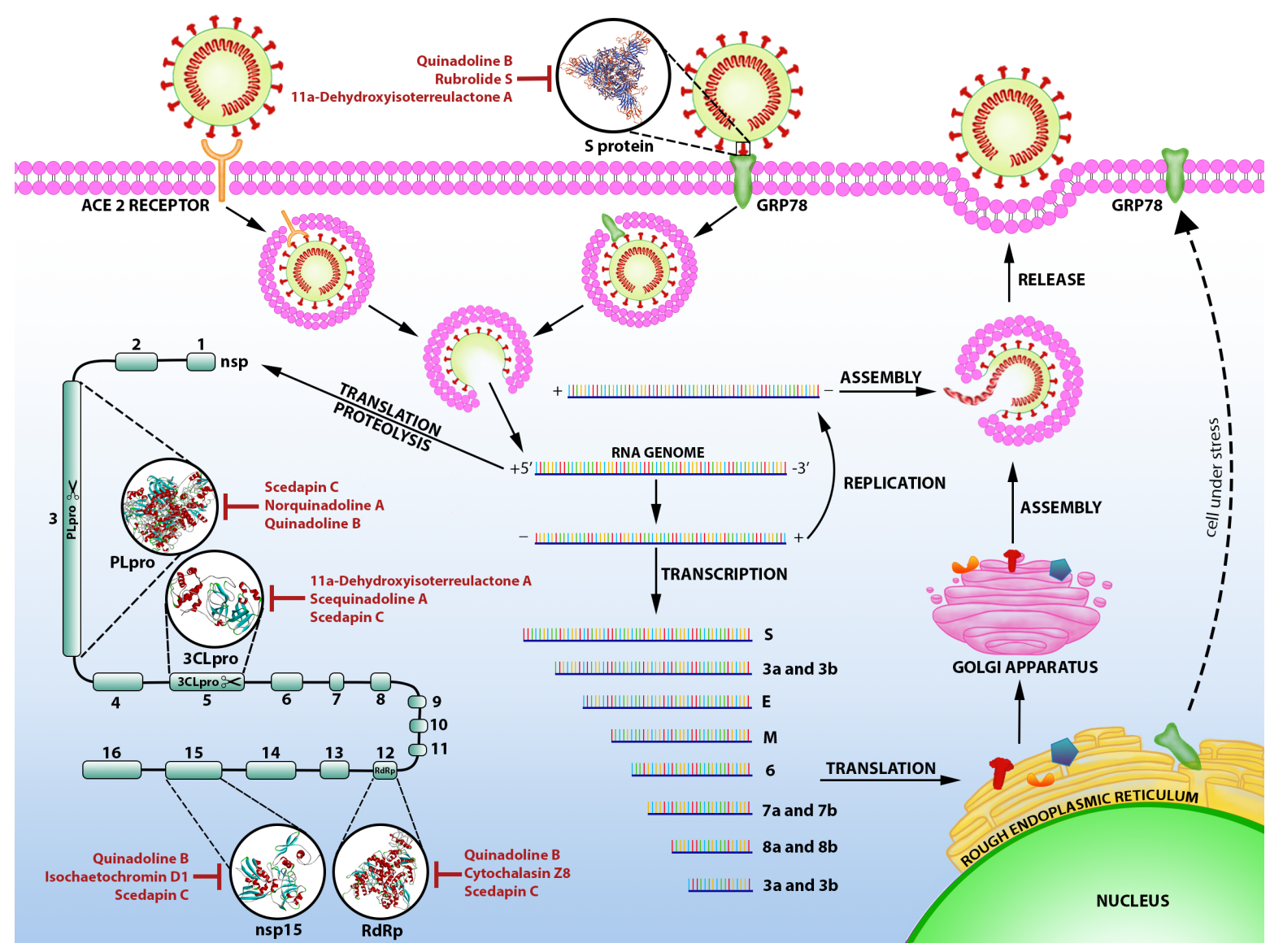

Figure 8. Pathways predictably inhibited by fungal natural products cytochalasin Z8 (4), isochaetochromin D1 (8), 11a-dehydroxyisoterreulactone A (11), scedapin C (15), scequinadoline A (16), quinadoline B (19), norquinadoline A (20) and rubrolide S (23) during SARS-CoV2 host-cell infection.

As a global call to discover potential drugs against SARS-CoV2 infection, a collection of ninety seven low molecular weight natural products from fungi underwent molecular docking-based virtual screening against five key target proteins: cysteine proteases (PLpro and 3CLpro), RdRp, nsp15, and spike protein. Among the fungal metabolites screened, five exhibited multi-enzyme inhibitory effects with high binding affinities toward the viral proteins of SARS-CoV2. Quinadoline B (19), scedapin C (15) and isochaetochromin D1 (8) were able to bind with high affinity to all viral proteins. Meanwhile, 11adehydroxyisoterreulactone A (11) and norquinadoline A (20) demonstrated high binding 
affinities to all but one. Compounds $\mathbf{1 1}$ and $\mathbf{2 0}$ did not exhibit significant binding affinity towards PLpro and spike protein, respectively.

Additionally, the pharmacokinetics of the biologically active fungal natural products was also predicted through elucidation of their ADMET (absorption, distribution, metabolism, excretion and toxicity) profiles in silico. Notably, the secondary metabolites 11a-dehydroxyisoterreulactone A (11), quinadoline B (19) and norquinadoline A (20) conferred high gastrointestinal (GI) absorption, poor blood-brain barrier penetrability and high drug-likeness as per Lipinski's rule of five. Quinadoline B (19), having an $S \log$ value of -3.87 , has the best solubility among the multitargeting metabolites. As per toxicity prediction, Interestingly, $\mathbf{1 1}$ and $\mathbf{2 0}$ did not demonstrate any form of toxicity. Despite being a high-risk irritant, 19 still remains a promising drug candidate for SARS-CoV2 because it did not confer mutagenic, tumorigenic, and reproductive toxicities. Therefore, these compounds can be used for further development of multitarget ligands against SARS-CoV2. The present work can be used as a framework for future development and discovery of novel multitarget compounds against COVID-19 disease.

\section{Conclusion}

As of April 2020, over two million cases of COVID-19 have been confirmed. Given the rapid transmissibility of the virus and the lack of specific drugs and vaccines, our computational-inspired study focused on repurposing previously known fungal secondary metabolites reported to have profound antiviral activities. Although RdRp and the cysteine proteases, 3CLpro and PLpro, have long been targeted in silico, our study focused on utilizing fungal secondary metabolites as potential inhibitors for these enzymes. It is noteworthy to mention that our study was first to report inhibitors that could target the spike-binding domain to GRP78 which mediates the secondary entry of the virus. Furthermore, this is also one of the few studies that identified inhibitors that could target nsp15 - a non-structural protein 
essential for evading host immunity. Of the fungal natural products that were virtually screened, we identified two fumiquinazoline alkaloids quinadoline B (19), scedapin C (15), and the polyketide isochaetochromin D1 (8) with strong inhibitory effects against the target viral proteins in SARS-CoV2. Finally, in silico ADMET prediction was performed to identify candidate compounds for lead optimization and drug development. Notably, quinadoline B (19) conferred high gastrointestinal (GI) absorption, poor blood-brain barrier penetrability and high drug-likeness as per Lipinski's rule of five. The present work can be used as a framework for future development and discovery of novel multitarget compounds against COVID-19 disease. Given the promising antiviral potential of quinadoline B (19), we now propose to modify or alter the functional moieties present in the compound to improve its biological activity and to mitigate its high-risk irritant effect. Acknowledging the use of iteration, in silico structural modification of quinadoline B (19) is a work in progress.

\section{Conflicts of Interest}

The authors declare no conflict of interest.

\section{Reference}

1. Fehr, A.R.; Perlman, S. Coronaviruses: An overview of their replication and pathogenesis. Methods Mol. Biol. 2015, 1282, 1-23. doi:10.1007/978-1-4939-243871

2. Dong, E.; Du, H.; Gardner, L. An interactive web-based dashboard to track COVID19 in real time. The Lancet 2020, 1-2. doi:10.1016/S1473-3099(20)30120-1

3. Liu, C.; Zhou, Q.; Li, Y.; Garner, L.V.; Watkins, S.P.; Carter, L.J.; Smoot, J.; Gregg, A.C.; Daniels, A.D.; Jervey, S.; Albaiu, D. Research and development on therapeutic agents and vaccines for COVID-19 and related human coronavirus diseases. ACS Cent. Sci. 2020, 6, 315-331. doi:10.1021/acscentsci.0c00272

4. Kitchen, D.B.; Decornez, H.; Furr, J.R.; Bajorath, J. Docking and scoring in virtual screening for drug discovery: Methods and applications. Nat. Rev. Dru. Discov. 2004, 3, 935-949. doi:10.1038/nrd1549

5. Elfiky, A.A. Anti-HCV, nucleotide inhibitors, repurposing against COVID-19. Life. Sci. 2020, 248, 1-6. doi:10.1016/j.1fs.2020.117477

6. Arya, R.; Das, A.; Prashar, V.; Kumar, M. Potential inhibitors against papain-like protease of novel coronavirus (COVID-19) from FDA approved drugs. ChemRxiv (preprint). doi:10.26434/chemrxiv.118 60011.v1 
7. Chen, Y.W.; Yiu, C.P.B.; Wong, K.Y. Prediction of the SARS CoV2 (2019-nCoV) 3C-like protease (3CLpro) structure: Virtual screening reveals velpatasvir, ledipasvir, and other drug repurposing candidates. F1000 Res. 2020, 9, 1-12. doi:10.12688/f1000research.22457.1

8. Pettersen, E.F.; Goddard, T.D.; Huang, C.C.; Couch, G.S.; Greenblatt, D.M.; Meng, E.C.; Ferrin, T.E. UCSF Chimera - A visualization system for exploratory research and analysis. J. Comput. Chem. 2004, 25, 1605-1612. doi:10.1002/jcc.20084.

9. Hanwell, M.D.; Curtis, D.E.; Lonie, D.C.; Vandermeerschd, T.; Zurek, E.; Hutchison, G.R. Avogadro: An advanced semantic chemical editor, visualization, and analysis platform. J. Cheminform. 2012, 4. doi:10.1186/1758-2946-4-17.

10. Wang, J.; Wang, W.; Kollman, P.A.; Case, D.A. Automatic atom type and bond type perception in molecular mechanical calculations. J. Mol. Graph. Model. 2006, 25, 247-260. doi:10.1016/j.jmgm.2005.12.005.

11. Yang, J.; Roy, A.; Zhang, Y. Protein-ligand binding site recognition using complementary binding-specific substructure comparison and sequence profile alignment. Bioinformatics. $\quad \mathbf{2 0 1 3}, \quad 29, \quad 2588-2595$. doi:10.1093/bioinformatics/btt447.

12. Trott, O.; Olson, A.J. Software news and update AutoDock Vina: Improving the speed and accuracy of docking with a new scoring function, efficient optimization, and multithreading. J. Comput. Chem. 2010, 31, 455-461. doi:10.1002/jcc.21334.

13. Macabeo, A.P.G.; Pilapil, L.A.E.; Garcia, K.Y.M.; Quimque, M.T.J.; Phukhamsakda, C.; Cruz, A.J.C.; Hyde, K.D.; Stadler, M. Alpha-glucosidase-and lipase-inhibitory phenalenones from a new species of Pseudolophiostoma originating from Thailand. Molecules 2020, 25, 1-9. doi:10.3390/molecules 25040 965

14. Phukhamsakda, C.; Macabeo, A.P.G.; Huch, V.; Cheng, T.; Hyde, K.D.; Stadler, M. Sparticolins A-G, biologically active oxidized spirodioxynaphthalene derivatives from the ascomycete Sparticola junci.J. Nat. Prod. 2019, 82, 2878-2885. doi:10.1021/acs.jnatprod.9b00604

15. Escobedo-González, R.; Vargas-Requena, C.L.; Moyers-Montoya, E.; AcevesHernández, J.M.; Nicolás-Vázquez, M.I; Miranda-Ruvalcaba, R. In silico study of the pharmacologic properties and cytotoxicity pathways in cancer cells of various indolylquinone analogues of perezone. Molecules 2017, 22, 1-23. doi:10.3390/molecules22071060

16. Bashyal, B.P.; Wellensiek, B.P.; Ramakrishnan, R.; Faeth, S.H.; Ahmad, N.; Gunatilaka, A.L. Altertoxins with potent anti-HIV activity from Alternaria tenuissima QUE1Se, a fungal endophyte of Quercus emoryi. Bioorg. Med. Chem. 2014, 22, 6112-6116. doi:10.1016/j.bmc.2014.08.039

17. Tan, S.; Yang, B.; Liu, J.; Xun, T.; Liu, Y.; Zhou, X. Penicillixanthone A, a marinederived dual-coreceptor antagonist as anti-HIV-1 agent. Nat. Prod. Res. 2019, 33, 1467-1471. doi:10.1080/14786419.2017.1416376

18. Pang, X.; Zhao, J.Y.; Fang, X.M.; Zhang, T.; Zhang, D.W.; Liu, H.Y.; Su, J.; Cen, $\mathrm{S}$.; Yu, L.Y. Metabolites from the plant endophytic fungus Aspergillus sp. CPCC 400735 and their anti-HIV activities. J. Nat. Prod. 2017, 80, 2595-2601. doi:10.1021/acs.jnatprod.6b00878

19. Zhao, J.; Feng, J.; Tan, Z.; Liu, J.; Zhao, J.; Chen, R.; Xie, K.; Zhang, D.; Li, Y.; Yu, L.; Chen, X. Stachybotrysins A-G, phenylspirodrimane derivatives from the fungus Stachybotrys chartarum.J. Nat. Prod. 2017, 80, 1819-1826. doi:10.1021/acs.jnatprod.7b00014

20. Liu, L.; Niu, S.; Lu, X.; Chen, X.; Zhang, H.; Guo, L.; Che, Y. Unique metabolites of Pestalotiopsis fici suggest a biosynthetic hypothesis involving a Diels-Alder 
reaction and then mechanistic diversification. ChemComm. 2010, 46, 460-462. doi:10.1039/B918330B

21. Singh, S.B.; Zink, D.L.; Goetz, M.A.; Dombrowski, A.W.; Polishook, J.D.; Hazuda, D. J. Equisetin and a novel opposite stereochemical homolog phomasetin, two fungal metabolites as inhibitors of HIV-1 integrase. Tetrahedron Lett. 1998, 39, 2243-2246. doi:10.1016/S0040-4039(98)00269-X

22. Singh, S.B.; Zink, D.L.; Bills, G.F.; Teran, A.; Silverman, K.C.; Lingham, R.B.; Felock, P.; Hazuda, D.J. Four novel bis-(naphtho- $\gamma$-pyrones) isolated from Fusarium species as inhibitors of HIV-1 integrase. Bioorg. Med. Chem. 2003, 13, 713-717. doi:10.1016/S0960-894X(02)01057-0

23. Huang, Z.; Nong, X.; Ren, Z.; Wang, J.; Zhang, X.; Qi, S. Anti-HSV-1, antioxidant and antifouling phenolic compounds from the deep-sea-derived fungus Aspergillus versicolor SCSIO 41502.Bioorg. Med. Chem. Lett. 2017, 27, 787-791. doi:10.1016/j.bmcl.2017.01.032

24. Nong, X.H.; Wang, Y.F.; Zhang, X.Y.; Zhou, M.P; Xu, X.Y.; Qi, S.H. Territrem and butyrolactone derivatives from a marine-derived fungus Aspergillus terreus. Mar. Drugs 2014, 12, 6113-6124. doi:10.3390/md12126113

25. Sandargo, B.; Michehl, M.; Praditya, D.; Steinmann, E.; Stadler, M.; Surup, F. Antiviral Meroterpenoid rhodatin and sesquiterpenoids rhodocoranes A-E from the wrinkled peach mushroom, Rhodotus palmatus. Org. 2019, 21, 3286-3289.

26. Huang, L.H.; Xu, M.Y.; Li, H.J.; Li, J.Q.; Chen, Y.X.; Ma, W.Z.; Li, Y.P.; Xu, J.; Yang, D.P.; Lan, W.J. Amino acid-directed strategy for inducing the marine-derived fungus Scedosporium apiospermum F41-1 to maximize alkaloid diversity. Org. lett. 2017, 19, 4888-4891. doi:10.1021/acs.orglett.7b 02238

27. Peng, J.; Lin, T.; Wang, W.; Xin, Z.; Zhu, T.; Gu, Q.; Li, D. Antiviral alkaloids produced by the mangrove-derived fungus Cladosporium sp. PJX-41. J. Nat. Prod. 2013, 76, 1133-1140. doi:10.1021/np400200k

28. He, F.; Bao, J.; Zhang, X.Y.; Tu, Z.C.; Shi, Y.M.; Qi, S.H. Asperterrestide A, a cytotoxic cyclic tetrapeptide from the marine-derived fungus Aspergillus terreus SCSGAF0162. J. Nat. Prod. 2013, 76, 1182-1186. doi:10.1021/np300897v

29. Zhu, T.; Chen, Z.; Liu, P.; Wang, Y.; Xin, Z.; Zhu, W. New rubrolides from the marine-derived fungus Aspergillus terreus OUCMDZ-1925. J. Antibiot. Res. 2014, 67, 315-318. doi:10.1038/ja.2013.135

30. Gao, H.; Guo, W.; Wang, Q.; Zhang, L.; Zhu, M.; Zhu, T.; Gu, Q.; Wang, W.; Li, D. Aspulvinones from a mangrove rhizosphere soil-derived fungus Aspergillus terreus Gwq-48 with anti-influenza A viral (H1N1) activity. Bioorg. Med. Chem. Lett. 2013, 23, 1776-1778. doi:10.1016/j.bmcl.2013.01.051

31. Wu, C.; Liu, Y.; Yang, Y.; Zhang, P.; Zhong, W.; Wang, Y.; Wang, Q.; Xu, Y.; Li, M.; Li, X.; Zheng, M. Analysis of therapeutic targets for SARS-CoV-2 and discovery of potential drugs by computational methods. Acta Pharm. Sin. B (preproof). doi:10.1016/j.apsb.2020.02.008

32. Chandel, V.; Raj, S.; Rathi, B.; Kumar, D. In silico identification of potent COVID19 main protease inhibitors from FDA approved antiviral compounds and active phytochemicals through molecular docking: A drug repurposing approach (preprint). doi:10.20944/preprints202003.0349.v1

33. Ortiz-Alcantara, J. Small molecule inhibitors of the SARS-CoV nsp15 endoribonuclease. Virus Adap. Treat. 2010, 2, 125-133. doi:10.2147/VAAT.S12733

34. Kindler, E.; Gil-Cruz, C.; Spanier, J.; Li, Y.; Wilhelm, J.; Rabouw, H.H.; Züst, R.; Hwang, M.; V'kovski, P.; Stalder, H.; Marti, S. Early endonuclease-mediated evasion of RNA sensing ensures efficient coronavirus replication. PLoS Path. 2017, 13, e1006195. doi:10.1371/journal.ppat.1006195 
35. Kim, Y.; Jedrzejczak, R.; Maltseva, N.I.; Endres, M.; Godzik, A.; Michalska, K.; Joachimiak, A. Crystal structure of Nsp15 endoribonuclease NendoU from SARSCoV-2. bioRxiv (preprint). doi:10.1101/2020. 03.02.968388

36. Ibrahim, I.M.; Abdelmalek, D.H.; Elfiky, A.A. GRP78: a cell's response to stress. Life Sci. 2020, 226, 156-163. doi:10.1016/j.lfs.2019.04.022

37. Quinones, Q.J.; Ridder, G.G.D.; Pizzo, S.V. GRP78, a chaperone with diverse roles beyond the endoplasmic reticulum. Histol. Histopathol. 2008, 23, 1409-1416. doi:10.14670/HH-23.1409

38. Ibrahim, I.; Abdelmalek, D.; Elshahat, M.; Elfiky, A. COVID-19 Spike-host cell receptor GRP78 binding site prediction. J. Inf. 2020. doi:10.1016/j.jinf.2020.02.026

39. Chu, H.; Chan, C.M.; Zhang, X.; Wang, Y.; Yuan, S.; Zhou, J.; Au-Yeung, R.K.; Sze, K.H.; Yang, D.; Shuai, H.; et al. Middle East respiratory syndrome coronavirus and bat coronavirus HKU9 both can utilize GRP78 for attachment onto host cells. $J$. Biol. Chem. 2018, 293, 11709-11726. doi: 10.1074/jbc.RA118.001897

40. Daina, A.; Michielin, O.; Zoete, V. SwissADME: a free web tool to evaluate pharmacokinetics, drug-likeness and medicinal chemistry friendliness of small molecules. Sci. Rep. 2017, 7, 42717. doi:10.1038/srep42717

41. Cheuka, P.M.; Mayoka, G.; Mutai, P.; Chibale, K. The role of natural products in drug discovery and development against neglected tropical diseases. Mol. 2017, 22 , 58. doi:10.3390/molecules22010058

42. Zaiyou, J.; Li, M.; Xiqiao, H. An endophytic fungus efficiently producing paclitaxel isolated from Taxus wallichiana var. mairei. Med. 2017, 96, 1-4. doi:10.1097/MD.0000000000007406

43. Hyde, K.D.; Xu, J.; Rapior, S.; Jeewon, R.; Lumyong, S.; Niego, A.G.T.; Abeywickrama, P.D.; Aluthmuhandiram, J.V.S.; Brahamanage, R.S.; Brooks, S.; et al. The amazing potential of fungi: 50 ways we can exploit fungi industrially. Fungal Divers. 2019, 97, 1-136. doi:10.1007/s13225-019-00430-9

44. Mapook, A.; Macabeo, A.P.G.; Thongbai, B.; Hyde, K.D., Stadler, M. Polyketidederived secondary metabolites from a dothideomycetes fungus, Pseudopalawania siamensis gen. et sp. nov.,(muyocopronales) with antimicrobial and cytotoxic activities. Biomolecules, 2020, 10, 569. doi:10.3390/biom10040569

45. Macabeo, A.P.G.; Cruz, A.J.C.; Narmani, A.; Arzanlou, M.; Babai-Ahari, A.; Pilapil, L.A.E.; Garcia, K.Y.M.; Huch, V.; Stadler, M. Tetrasubstituted $\alpha$-pyrone derivatives from the endophytic fungus, Neurospora udagawae. Phytochem. Lett. 2020, 35, 147151. doi:10.1016/j.phtol.2019.11.010

46. Phukhamsakda, C.; Macabeo, A.P.G.; Yuyama, K.T.; Hyde, K.D.; Stadler, M. Biofilm inhibitory abscisic acid derivatives from the plant-associated dothideomycete fungus, Roussoella sp.Molecules, 2018, 23, 2190. doi:10.3390/molecules23092190

47. Kuephadungphan, W.; Macabeo, A.P.G., Luangsa-Ard, J.J.; Tasanathai, K.; Thanakitpipattana, D.; Phongpaichit, S.; Yuyama, K.; Stadler, M. Studies on the biologically active secondary metabolites of the new spider parasitic fungus Gibellula gamsii. Mycol. Prog. 2019, 18, 135-146. doi:10.1007/s11557-018-1431-4

48. Notarte, K.I.R.; Devanadera, M.K.P.; Mayor, A.B.R.; Cada, M.C.A., Pecundo, M.H.; Macabeo, A.P.G. Toxicity, antibacterial, and antioxidant activities of fungal endophytes Colletotrichum and Nigrospora spp. isolated from Uvaria grandiflora. Phil. J. Sci. 2019, 148, 503-510.

49. Notarte, K.I.; Yaguchi, T.; Suganuma, K.; dela Cruz, T.E. Antibacterial, cytotoxic and trypanocidal activities of marine-derived fungi isolated from Philippine macroalgae and seagrasses. Acta Bot. Croat. 2018, 77, 141-151. doi:10.2478/botcro2018-0016 
50. Notarte, K.; Nakao, Y.; Yaguchi, T.; Bungihan, M.; Suganuma, K.; dela Cruz, TE. Trypanocidal activity, cytotoxicity and histone modifications induced by malformin A1 isolated from the marine-derived fungus Aspergillus tubingensis IFM 63452. 2017, Mycosphere, 8, 111-120. doi:10.5943/mycosphere/8/1/10

51. Rothan, H.A.; Byrareddy, S.N. The epidemiology and pathogenesis of coronavirus disease (COVID-19) outbreak. J. Autoimmun. 2020, 102433, 1-4. doi:10.1016/j.jaut.2020.102433

52. Chen, Y.; Liu, Q.; Guo, D. Coronaviruses: Genome structure, replication, and pathogenesis. J. Med. Virology 2020, 92, 418-423. doi:10.1002/jmv.25681 